\title{
Depression and anxiety symptoms in young adults before and during the COVID-19 pandemic: evidence from a Canadian population-based cohort
}

Kia Watkins-Martin 1,2, Massimiliano Orri 1,15, Marie-Hélène Pennestri ${ }^{2,3,4}$, Natalie Castellanos-Ryann, Simon Larose ${ }^{8}$, Jean-Philippe Gouin ${ }^{9}$, Isabelle Ouellet-Morin ${ }^{10,11}$, Nicholas Chadi ${ }^{6,7}$, Frederick Philippe ${ }^{12}$, Michel Boivin ${ }^{13}$, Richard E. Tremblay ${ }^{4}$, Sylvana Côté6,14,15 and Marie-Claude Geoffroy ${ }^{1,2^{*}}$

\begin{abstract}
Background: Concerns have been raised that the COVID-19 pandemic could increase risk for adverse mental health outcomes, especially in young adults, a vulnerable age group. We investigated changes in depression and anxiety symptoms (overall and severe) from before to during the pandemic, as well as whether these changes are linked to COVID-19-related stressors and pre-existing vulnerabilities in young adults followed in the context of a populationbased cohort.

Method: Participants ( $n=1039$ ) from the Quebec Longitudinal Study of Child Development reported on their depression (Centre for Epidemiological Studies Depression Scale, short form) and anxiety (General Anxiety Disorder-7 Scale) symptoms and completed a COVID-19 questionnaire during the first wave of the COVID-19 pandemic in the summer of 2020 (age 22 years). Assessments at age 20 (2018) were used to estimate pre-pandemic depression and anxiety symptom severity.
\end{abstract}

Results: While mean levels of depression and anxiety symptoms did not change from before to during the first wave of the COVID-19 pandemic (e.g., the mean of depressive symptoms was 9.30 in 2018 and 9.59 in 2020), we observed a slight increase in rates of severe depression (scores $\geq 21$ ) from before $(6.1 \%)$ to during (8.2\%) the pandemic. Most COVID-19-related variables (e.g., loss of education/occupation, frequent news-seeking) - except living alone - and most pre-existing vulnerabilities (e.g., low SES, low social support) were not associated with changes in depression or anxiety symptoms. However, results varied as a function of pre-pandemic levels of depression and anxiety: depression and anxiety symptoms increased among adults with the lowest levels of symptoms before the pandemic, while they decreased among those with the highest levels of symptoms, possibly reflecting a regression to the mean.

Conclusions: Depression and anxiety symptoms in young adults from Québec in Summer 2020 were mostly comparable to symptoms reported in 2018. Most COVID-19-related stressors and pre-existing vulnerabilities were not associated with changes in symptoms, except living alone and pre-existing symptoms of depression and anxiety. However, the increased rate of severe depression warrants further investigation.

*Correspondence: marie-claude.geoffroy@mcgill.ca

${ }^{2}$ Department of Educational and Counselling Psychology, McGill University, Montreal, QC H3A 1Y2, Canada

Full list of author information is available at the end of the article

(c) The Author(s) 2021. Open Access This article is licensed under a Creative Commons Attribution 4.0 International License, which permits use, sharing, adaptation, distribution and reproduction in any medium or format, as long as you give appropriate credit to the original author(s) and the source, provide a link to the Creative Commons licence, and indicate if changes were made. The images or other third party material in this article are included in the article's Creative Commons licence, unless indicated otherwise in a credit line to the material. If material is not included in the article's Creative Commons licence and your intended use is not permitted by statutory regulation or exceeds the permitted use, you will need to obtain permission directly from the copyright holder. To view a copy of this licence, visit http://creativecommons.org/licenses/by/4.0/. The Creative Commons Public Domain Dedication waiver (http://creativeco mmons.org/publicdomain/zero/1.0/) applies to the data made available in this article, unless otherwise stated in a credit line to the data. 
Keywords: COVID-19, Mental health, Depression, Anxiety, Young adults

\section{Background}

There is concern that the coronavirus disease 2019 (COVID-19) pandemic has negatively impacted depressive and anxiety symptoms $[1,18,33]$, especially among young adults aged $18-25$ years $[10,20,26,36]$. While young adulthood is generally a period of good physical health, mental health problems are common [19, 27]. To date, most studies that have documented putative mental health consequences of the COVID-19 pandemic have relied on cross-sectional investigations of convenience samples [21, 25, 34, 38], from which it is not possible to draw conclusions about whether and how mental health has changed from pre-pandemic levels. Only longitudinal studies with pre-pandemic assessments of depression and anxiety symptoms can allow one to quantify such changes according to a clear temporal sequence and account for such sources of bias as seasonality. The few longitudinal studies with pre-pandemic assessments of depression and anxiety symptoms in young adults have yielded inconsistent findings, with some showing deterioration $[5,42]$ and others reporting no symptom change during the COVID-19 pandemic.

To our knowledge, no population-based study in the Canadian province of Quebec has examined whether the mental health of young adults has changed from before to during the first wave of the pandemic and identified factors associated with these changes. Using a longitudinal population-based cohort of young adults from Quebec, where strict lockdown measures (e.g., stay-at-home orders; social distancing; school and business closures) were implemented at the beginning of the first wave of the COVID-19 pandemic, we aimed to: (1) examine whether and how depression and anxiety symptoms and the severity of these symptoms changed from the pre-pandemic (participant age: 20 years) to the intrapandemic period during the summer of 2020 (participant age: 22 years); and (2) investigate whether these changes were linked to COVID-19-related stressors (e.g., loss of employment/education; COVID-19-related news-seeking) and/or pre-existing vulnerabilities (e.g., low SES; severe depression and anxiety).

\section{Method}

\section{Participants}

The Québec Longitudinal Study of Child Development (QLSCD) [28] is an ongoing population-based cohort that includes 2120 participants born in 1997/98 in the province of Quebec, Canada. From July to August 2020, participants completed an online survey at age 22 years about their well-being during the COVID-19 pandemic. Of the 1593 individuals contacted, 1182 responded in 2020 (participation rate: 74\%). Of those, 1039 had provided information on their mental health before the pandemic in the Spring of 2018, at age 20 years. The QLSCD, conducted by the Institut de la Statistique du Québec (ISQ) [9], was approved by ethical committees of the ISQ and the CHU Sainte-Justine Hospital Research Centre and written informed consent was obtained.

\section{Measures \\ Depression and anxiety symptoms before (20 years) and during (22 years) the COVID-19 pandemic}

Depressive symptoms were self-reported using the Centre for Epidemiological Studies-Depression Scale, short form, (CES-D) including 12 items; (e.g., "I felt depressed") rated from $0=$ rarely/never to $3=\mathrm{most} / \mathrm{all}$ of the time [13, 35, 37]. Anxiety symptoms were self-reported using the Generalized Anxiety Disorder 7-item scale (GAD-7) including 7 items (e.g., "Feeling nervous, anxious or on edge") rated from $0=$ not at all to $3=$ nearly every day [43]. Scores of 21 to 36 and of 15 to 21 are thought to indicate severe levels of depression and anxiety, respectively [37].

\section{COVID-19-related stressors}

All participants completed a questionnaire assessing their worries about the pandemic. Participants indicated their level of concern on a 4-point Likert scale $(1=$ not at all to $4=$ extremely concerned) regarding: having a degree/certificate/diploma which will not be considered equivalent, compared to those who completed their degree prior to the pandemic; not having job prospects in the near future; and not having enough money to meet basic needs. The questionnaire also included items about their living status (alone vs. with others) and the level of disruption that the pandemic had on their life from midMarch to Summer 2020, including: loss of employment ("I lost my job"; "I closed my business"); loss of education ("All or some of my courses have been rescheduled to Fall 2020"; "I have dropped all my courses"; "My internship has been postponed or cancelled"); a positive COVID-19 test result (yes vs. no); COVID-19-related daily newsseeking on traditional or social media $(<2 \mathrm{~h}$ vs. $\geq 2 \mathrm{~h}$ per day); and participants' geographic region based on their postal code (Montreal vs. other regions, as Montreal was the hardest hit region in the Province of Québec in March-August 2020, as per the number of confirmed cases and COVID-19-related deaths) [7]. 


\section{Pre-existing vulnerabilities}

Pre-existing vulnerabilities increasing risk for poor mental health $[12,14,24,31,41,47]$ were assessed before the Québec government enforced lockdown measures as of mid-March 2020: not in education or employment at 22 years (just prior to the onset of the pandemic); having parents of low socioeconomic status (SES) (defined as scores $\leq 1$ standard deviation (SD) on SES scale aggregating annual gross income, parental education level, and parental occupational prestige from ages 15 and 17 years) [46]; sexual orientation at 17 years (same sex/bisexual/ asexual vs. opposite sex; if missing at 17 years, orientation at 15 years was used); low social support at 19 years (defined as score $\leq 1$ SD on the 10-item Social Provision Scale) [4]; low life satisfaction at 19 years old (defined as a score of $\leq 5$ on the following item: "Using a scale of 0 to 10 , where 0 means 'very dissatisfied' and 10 means 'very satisfied', how do you feel about your life as a whole right now?") [44]; and a chronic learning disability diagnosis as reported by the mother at 15 or 17 years (no vs. yes).

\section{Statistical analyses}

All statistical analyses were conducted in IBM SPSS, version 26, using cohort weights to ensure representativeness of the sample. First, we described the COVID19-related stressors and pre-existing vulnerabilities variables using counts and percentages. Second, we tested whether (a) a mean symptom score and (b) a severity category of depressive and anxiety symptoms changed from before to during the COVID-19 pandemic using paired t-tests. Third, we calculated change in depression and anxiety symptoms by subtracting the mean symptom score before the pandemic ( 20 years) to the mean score during the pandemic (22 years). We standardized the mean change score (change/SD of change) to ease interpretation; positive scores indicate an increase in depression and anxiety symptoms. Then, we examined crude associations between COVID-19-related stressors and pre-existing vulnerabilities variables and change in depression and anxiety symptoms, using $\mathrm{t}$-tests and ANOVAs. The double-sided p-value for significance was set at 0.05 . We used multiple imputation (MI) to generate 100 datasets to handle missing values on risk factors. Missing values ranged from $0.9 \%$ (loss of employment) to $17.9 \%$ (sexual minority); there was no missing data for COVID-19-related stressors.

\section{Results}

Descriptive statistics on COVID-19-related stressors and pre-existing vulnerabilities are shown in Table 1. Figure 1 depicts descriptive statistics for COVID-19-related
Table 1 Descriptive statistics of the COVID-19-related stressors and pre-existing vulnerabilities, weighted

\section{n $\quad \%$}

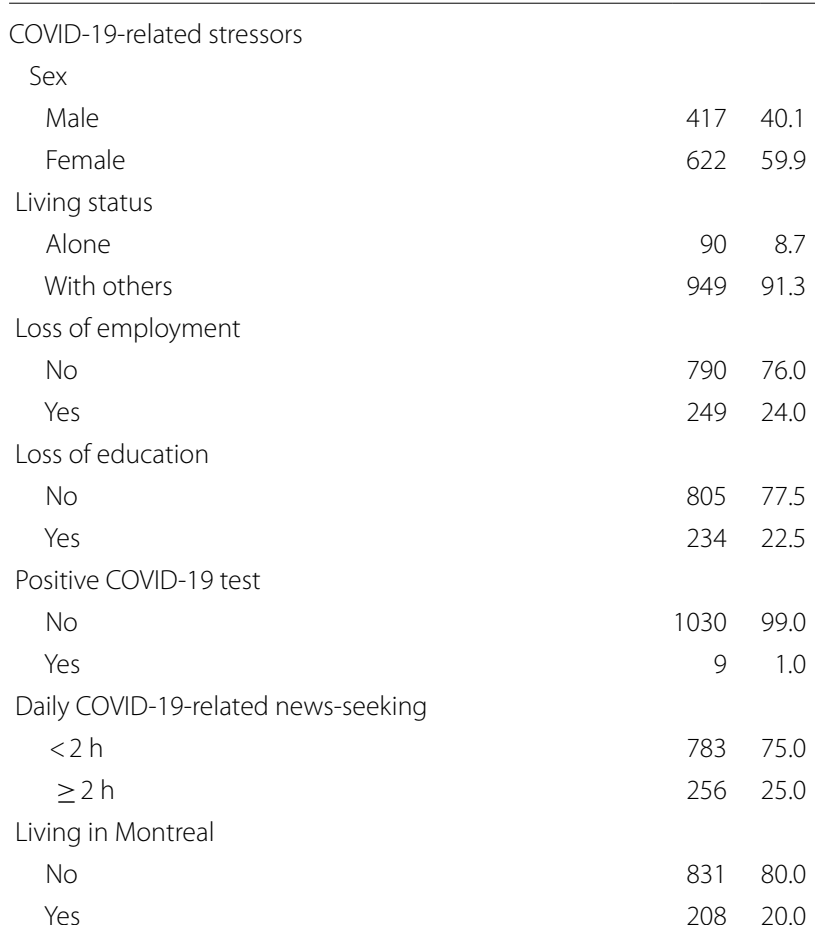

Pre-existing vulnerabilities

Not in education or employed (22 years, pre-pandemic) $\begin{array}{rrr}\text { No } & 941 & 90.6 \\ \text { Yes } & 98 & 9.4\end{array}$

Low SES families $(15,17 \text { years })^{\text {a }}$

No

$873 \quad 84.0$

Yes

Sexual minority $(15,17$ years $)$

No

$921 \quad 88.6$

Yes (Gay, Lesbian, Asexual) $\quad 118 \quad 11.4$

Low social support (19 years) ${ }^{\text {a }}$

No

$892 \quad 87.3$

Yes

Low life satisfaction (19 years)

No

$901 \quad 86.7$

Yes

Learning disability diagnosis (15, 17 years)

No

Yes

Pre-existing depression symptoms (20 years)

No/low/moderate

Severe ${ }^{c}$

$64 \quad 6.2$

Pre-existing anxiety symptoms (20 years)

No/low/moderate

$990 \quad 95.3$

Severe ${ }^{c}$ 
Table 1 (continued)

Data were compiled from the final master file of the Québec Longitudinal Study of Child Development (1998-2020), Québec Government, Québec Statistic Institute

Maximum $\mathrm{N}$ available ranges from 869 to 1039

a Defined as scores $<1$ standard deviation of the sample mean

${ }^{\text {b }}$ Defined as scores of 0 to 5 a scale of 0 to 10 , where 0 means 'very dissatisfied' and 10 means 'very satisfied'

' Severe symptoms were defined by Centre for Epidemiological StudiesDepression scale scores $\geq 21$ and Generalized Anxiety Disorder 7-item scale scores $\geq 15$

concerns. The vast majority of young adults reported that they were "not at all concerned" about (a) having a compromised diploma; (b) loss of job prospects or (c) having enough money to meet basic needs, whereas 10.2, 21.4 and $14.0 \%$ reported that they were 'very or extremely concerned', respectively. As shown in Table 2, there was no difference in the means of depression and anxiety symptoms from before to during the pandemic, as reported by participants in July-August 2020. However, while the prevalence of severe anxiety did not increase significantly, that of severe depression did, with $6.2 \%$ of participants reporting severe depressive symptoms before the pandemic compared to $8.1 \%$ during the pandemic (increase of $1.9 \% ; \mathrm{p}=0.041$ ).

Figure 2 and Additional file 1: Table S1 depict standardized change in depression and anxiety from before the pandemic ( 20 years) to during the pandemic (22 years) as a function of COVID-related stressors. Symptoms of depression and anxiety did not vary according to COVID19-related stressors, except for participants living alone

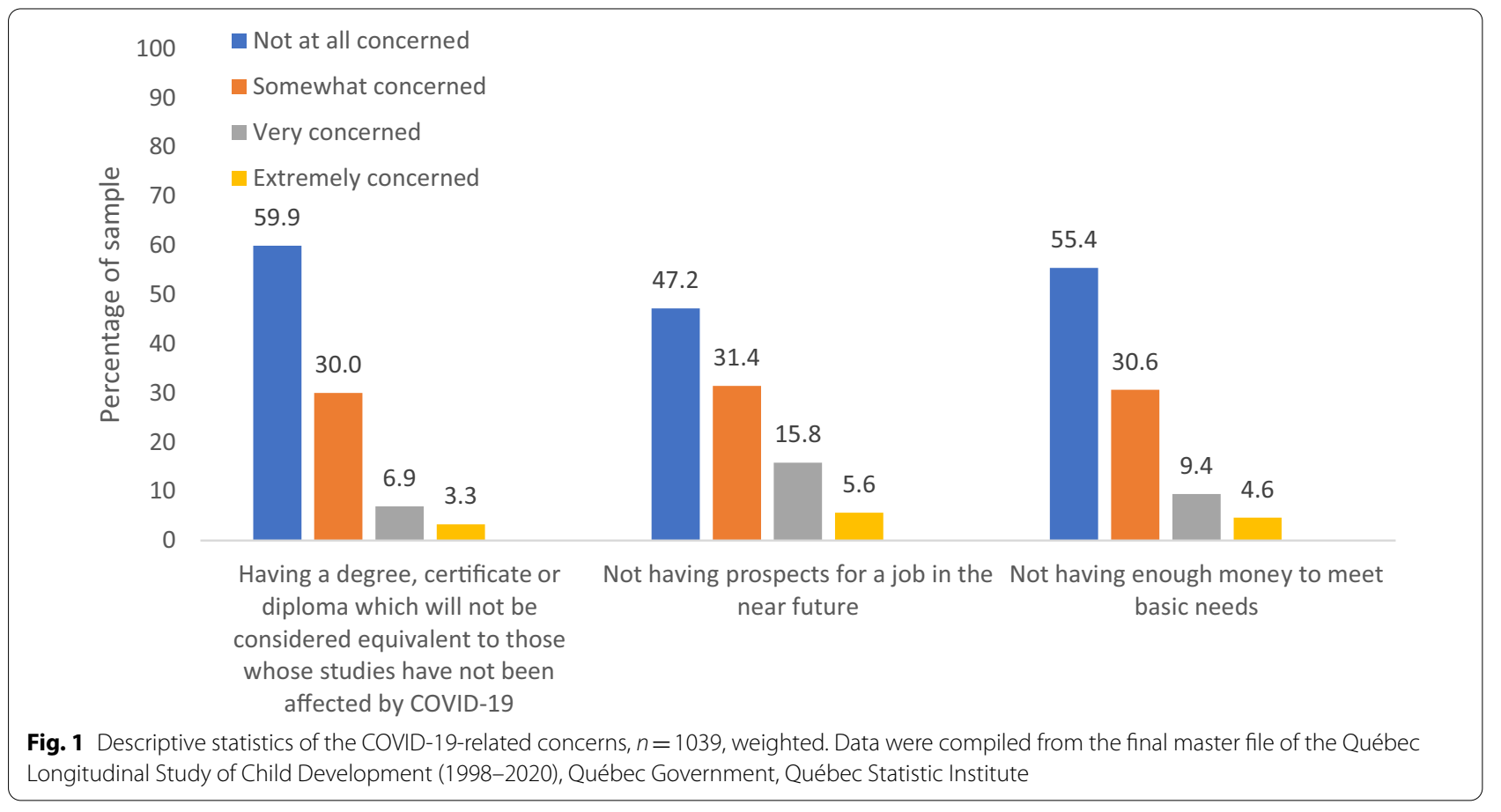

Table 2 Descriptive statistics for depression and anxiety symptoms before (20 years) and during (22 years) the COVID-19 pandemic, $n=1039$, weighted

\begin{tabular}{|c|c|c|c|}
\hline & $\begin{array}{l}\text { Before COVID-19 pandemic } \\
(20 y)\end{array}$ & $\begin{array}{l}\text { During COVID-19 pandemic } \\
(22 y)\end{array}$ & $\begin{array}{l}P \text { Value for differences } \\
\text { before vs. during the } \\
\text { pandemic }\end{array}$ \\
\hline Depressive symptoms, mean (SD) & $9.30(6.42)$ & 9.59 (6.79) & .153 \\
\hline Severe depression symptoms, $N(\%)^{\text {a }}$ & $64(6.2 \%)$ & $80(8.1 \%)$ & .041 \\
\hline Anxiety symptoms, mean (SD) & $4.73(4.61)$ & $4.45(4.70)$ & .060 \\
\hline Severe anxiety symptoms, $\mathrm{N}(\%)^{\mathrm{a}}$ & $51(4.9 \%)$ & $49(4.7 \%)$ & .807 \\
\hline
\end{tabular}

Data were compiled from the final master file of the Québec Longitudinal Study of Child Development (1998-2020), Québec Government, Québec Statistic Institute

a Severe symptoms were defined by Centre for Epidemiological Studies-Depression scale scores $\geq 21$ and Generalized Anxiety Disorder 7-item scale scores $\geq 15$ 


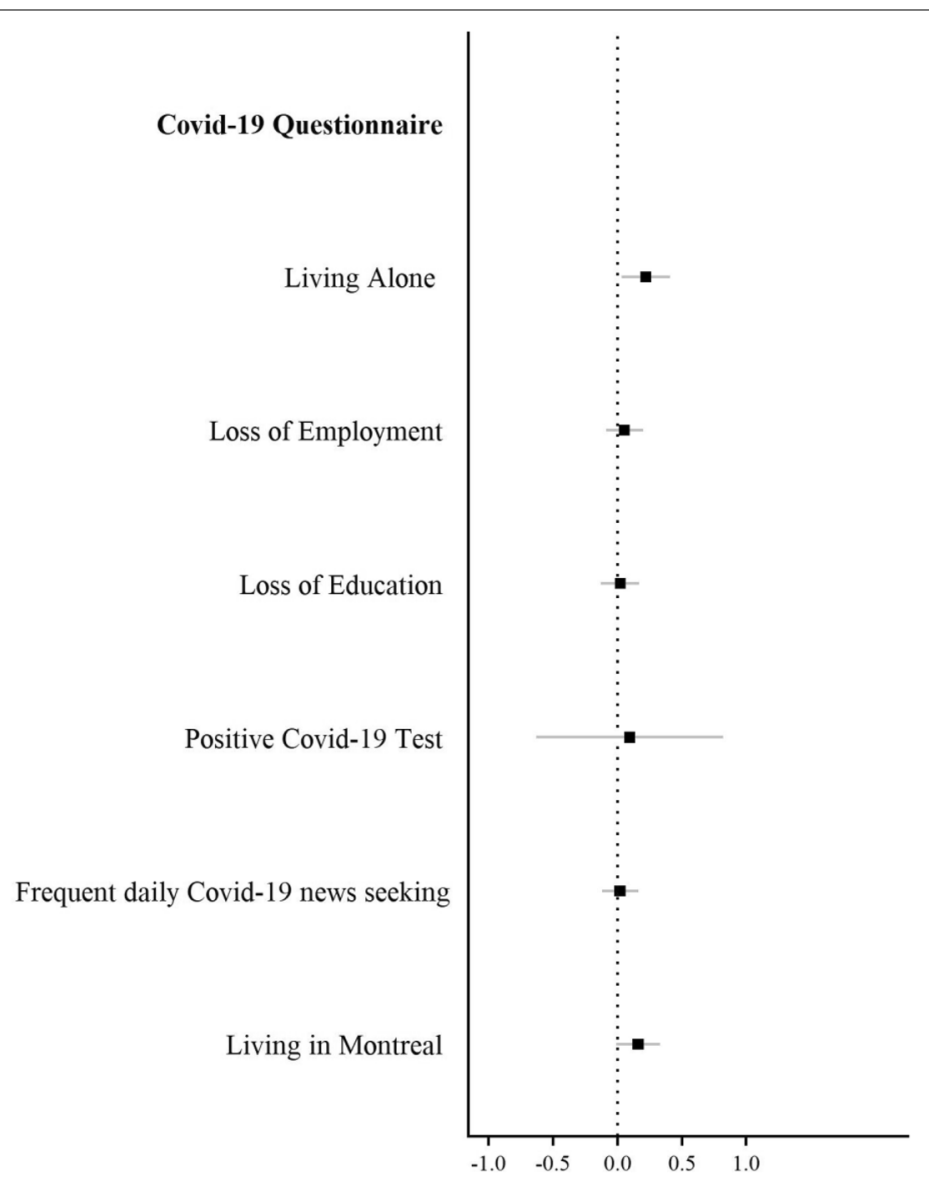

Change in Depression Z-Scores

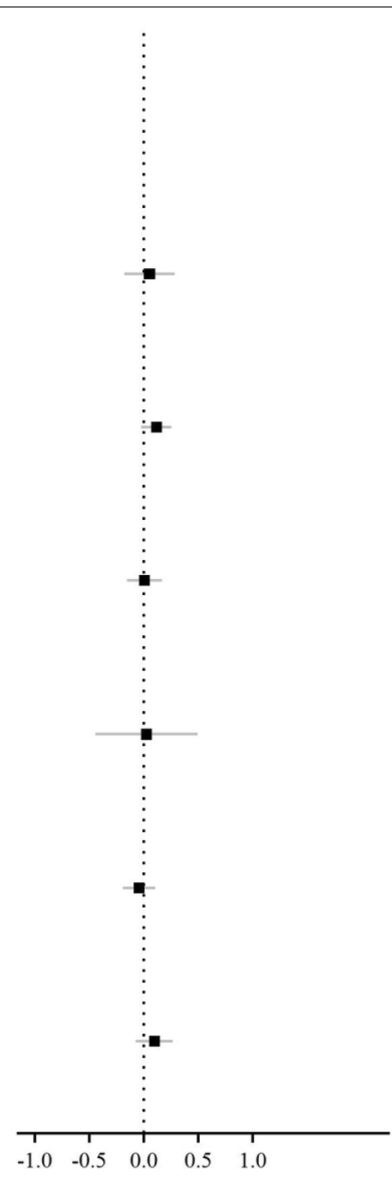

Change in Anxiety Z-Scores

Fig. 2 Change in depression and anxiety Z-scores from before (age 20 years) to during the COVID-19 pandemic (age 22 years) as a function of variables in the COVID-19 questionnaire; $n=1039$, weighted. Data were compiled from the final master file of the Québec Longitudinal Study of Child Development (1998-2020), Québec Government, Québec Statistic Institute. Positive scores indicate a deterioration of mental health

who reported a slight increase in depressive symptoms (0.22, SD). Figure 3 and Additional file 1: Table S1 depict standardized changes in depression and anxiety symptoms as a function of pre-existing vulnerabilities. Participants with pre-existing severe symptoms of depression and anxiety experienced a significant decrease in depressive and anxiety symptoms from before to during the pandemic. That is, individuals with severe depression at age 20 years experienced a decrease in depressive symptoms from 20 to 22 years (1.26 SD), while those with severe anxiety experienced a decrease in anxiety symptoms of 1.61 SD. In sensitivity analyses, we divided participants into quintiles according to their depressive and anxiety levels at 20 years: (1) very low $(0-20 \%)$; (2) low (21-40\%); (3) average (41-60\%); (4) high (61-80\%); and (5) very high (81-100\%) and explored changes in symptom levels from before to during COVID-19 using ANOVAs. As depicted in Fig. 4 and Additional file 2: Table S2, there was a significant increase in depression and anxiety symptoms among young adults with the lowest levels of symptoms at baseline. To illustrate, participants with very low levels of depressive symptoms at age 20 years experienced a significant increase in symptoms from age 20 to 22 years $(0.49 \mathrm{SD}, p<0.001)$, while those with very low levels of anxiety experienced an increase in symptoms of $0.38 \mathrm{SD}(p<0.001)$. As previously reported, young adults with the highest levels of depression and anxiety symptoms at baseline experienced a decrease in symptoms from before to during COVID-19.

\section{Discussion}

Using a population-based cohort of young adults with data collected 2 years before the pandemic and 4 months after the onset of the first wave of the pandemic (Summer 2020) in the province of Quebec, this study examined changes in symptoms of depression 


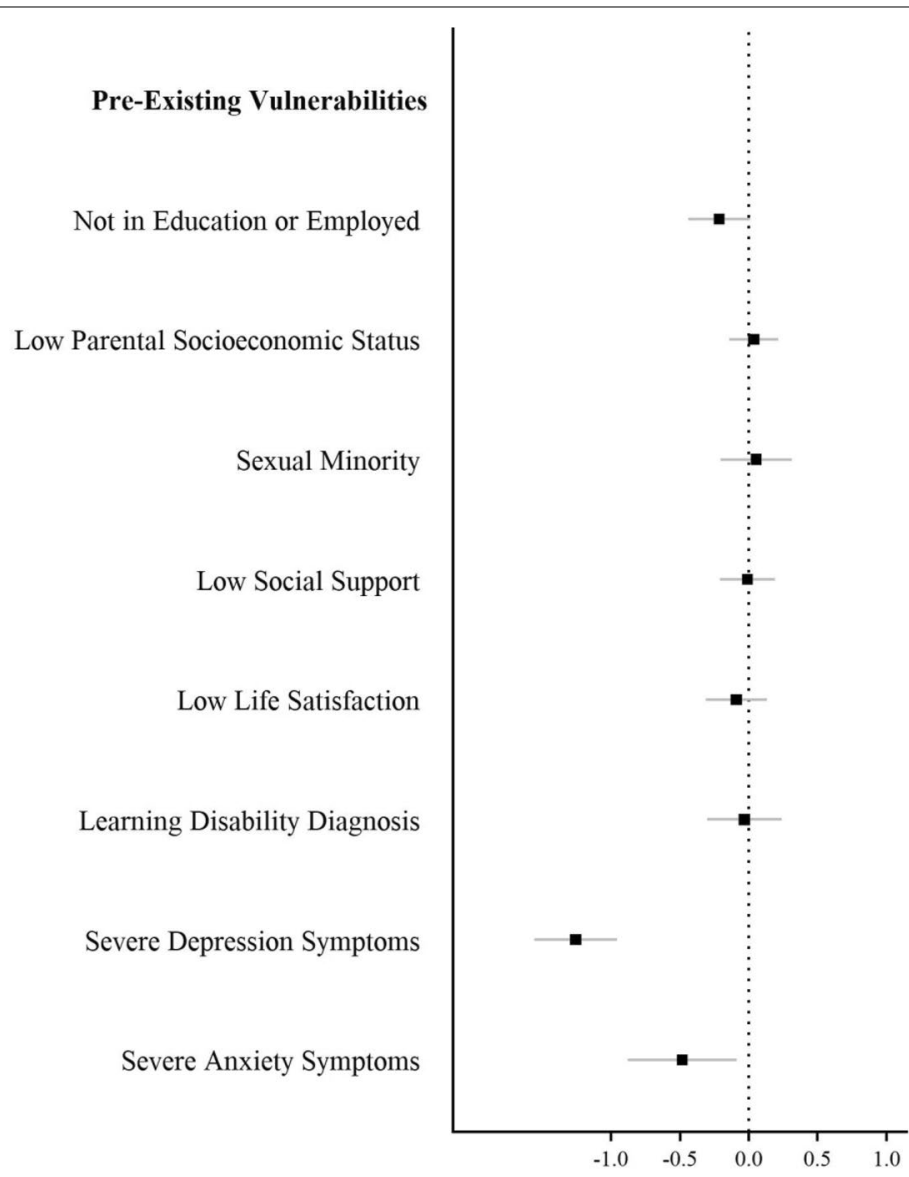

Change in Depression Z-Scores

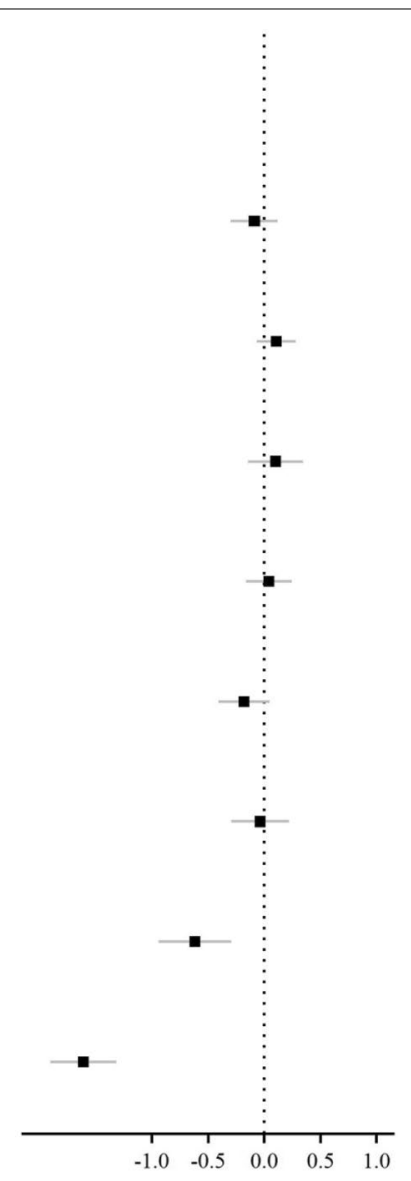

Change in Anxiety Z-Scores

Fig. 3 Change in depression and anxiety Z-scores from before (age 20 years) to during the COVID-19 pandemic (age 22 years) as a function of pre-existing vulnerabilities; $n=1039$, weighted. Data were compiled from the final master file of the Québec Longitudinal Study of Child Development (1998-2020), Québec Government, Québec Statistic Institute. Positive scores indicate a deterioration of mental health

and anxiety and investigated whether these changes are linked to pandemic-related stressors and/or pre-existing vulnerabilities. On average, young adults did not report change in depression and anxiety levels across the full spectrum of symptom severity. However, the prevalence of severe depressive symptoms increased by $1.9 \%$ during the initial months of the pandemic, while there was no change in severe anxiety symptoms. Most COVID-19-related stressors (with the exception of living alone) and variables pertaining to pre-existing vulnerabilities (e.g., low SES, low social support) were not associated with changes in symptoms of depression and anxiety. Contrary to expectations [5, 42], we did not observe a generalized worsening of depressive and anxiety symptoms during the pandemic among participants with severe pre-pandemic depression and anxiety. However, supplemental analyses investigating changes in depression and anxiety symptoms according to different levels of pre-existing symptoms (very low; low; average; high; very high) revealed that young adults with low levels of symptoms before the pandemic experienced a deterioration in mental health during the pandemic. Conversely, those with high levels of pre-existing symptoms at age 20 years experienced an improvement at age 22 years.

Our findings showing no increase in depression and anxiety symptoms from before to during the pandemic are comparable to a prior longitudinal study [42] using a sample of 768 young adults living in Switzerland. This study found that internalizing symptoms (assessed using depressive, anxiety, and suicidal ideation and self-injury items from the Social Behavior Questionnaire) did not significantly increase from before (20 years) to during the pandemic in April 2020 (22 years). In contrast, a study of 624 undergraduate students (mean age: 19.6 years) in Baoding, China, found that symptoms of depression 
A

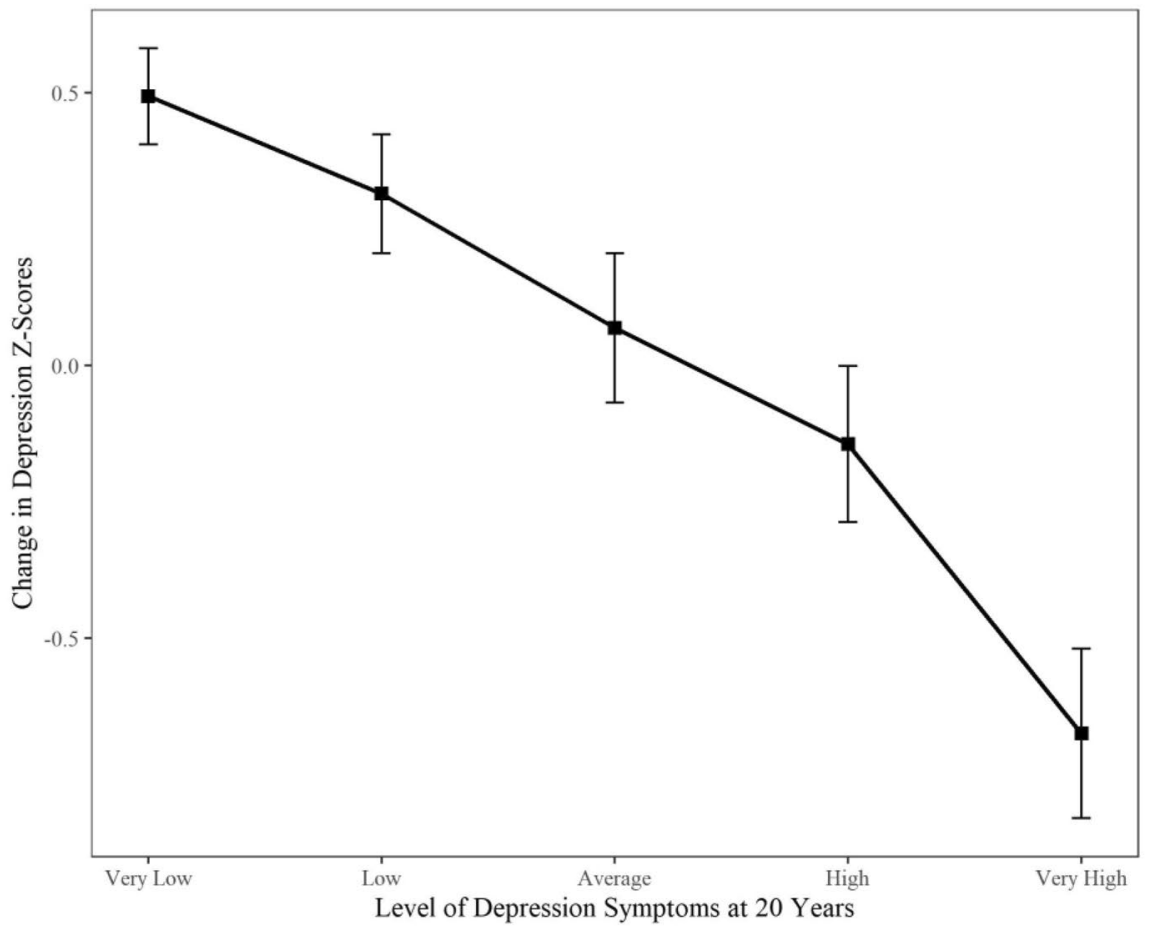

B

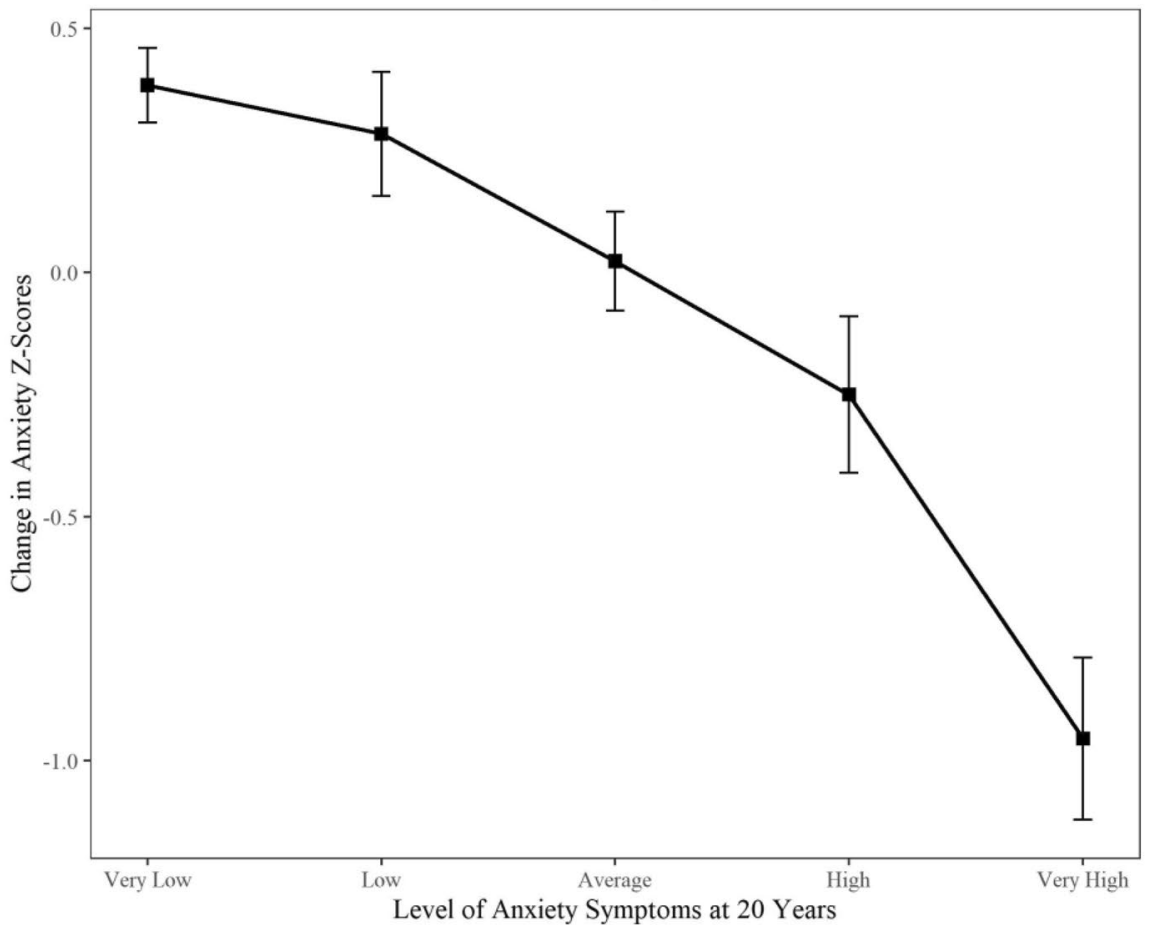

Fig. 4 Change in $\mathbf{A}$ depression and $\mathbf{B}$ anxiety Z-scores from before (age 20 years) to during the COVID-19 pandemic (age 22 years) as a function of categories of levels of pre-existing symptoms; $n=1039$, weighted. Data were compiled from the final master file of the Québec Longitudinal Study of Child Development (1998-2020), Québec Government, Québec Statistic Institute. Positive scores indicate a deterioration of mental health 
and anxiety (as measured by the PHQ-4) significantly increased from before (December 2019) to during the pandemic (February 2020) [22].

Although on average we did not observe changes across the full spectrum of symptom severity, the prevalence of severe depression slightly increased by $1.9 \%$ from before to during the pandemic. However, the prevalence of severe anxiety did not change, suggesting that mental health consequences of the pandemic might differ depending on the type of symptom. This is in line with a recent systematic review and meta-analysis of 65 longitudinal cohort studies by Robinson and colleagues that found that compared to symptoms of anxiety, increases in depressive symptoms tended to be larger and remained elevated beyond the first months of the pandemic [40].

None of the COVID-19-related stressors were associated with a change in depression and anxiety symptoms, except for those living alone who experienced a slight increase in depressive symptoms. These findings are in line with results from a large prospective panel study weighted to population proportions $(n=36,520)$ and conducted over the first 20 weeks of lockdown in the UK that identified living alone as a risk factor for higher symptoms of depression and anxiety during the pandemic. While most pre-existing vulnerabilities were not associated with change in depression and anxiety symptoms, we found that participants with pre-existing severe manifestations of depression and anxiety at age 20 years experienced a significant decrease in depressive and anxiety symptoms between 2018 and the summer of 2020 . Pre-existing mental health vulnerabilities have been identified in several cross-sectional studies as a risk factor for mental health deterioration during the pandemic $[15,29$, $39,45,48$ ], yet evidence from longitudinal studies is relatively scarce and contradictory, to date [40]. To illustrate, in a longitudinal study conducted on three psychiatry case-control cohorts in the Netherlands $(N=1517$, mean age: 56.1 years), the COVID-19 pandemic did not seem to exacerbate the severity of pre-existing symptoms among those with severe pre-pandemic mental health problems [30], which researchers suggested might be explained by stay-at-home orders allowing for the implementation of more structured and consistent daily routines [30,32]. In contrast, a cohort study on young adults in Switzerland identified pre-pandemic emotional distress as the largest risk factor for increased emotional distress during the pandemic [42].

In our study, symptoms of youth with severe pre-existing symptoms did not deteriorate but rather improved, possibly reflecting a natural improvement of mental illness over time, an effect of seasonality (2018 data were collected in the spring, while 2020 data were collected in the summer), or a reduction in social stressors during periods of confinement. Conversely, young adults with low levels of depression and anxiety symptoms experienced a significantly greater deterioration in mental health from before to during the pandemic. These results correspond with findings from a longitudinal study by Hamza and colleagues conducted with students at a Canadian university $(N=773)$, in which participants with pre-existing mental health problems showed decreasing depressive and anxiety symptoms from before (May 2019) to during (May 2020) the pandemic, whereas their peers without pre-existing mental health problems showed increasing depressive and anxiety symptoms during the pandemic [17]. Importantly, such findings might reflect the negative impact of increased social isolation (due to widespread closures and social distancing regulations) on young adults without pre-existing mental health problems. However, we cannot rule out the possibility that these findings merely reflect a regression to the mean, a statistical phenomenon that makes values that are extreme at the first point of measurement more likely to be closer to the distribution mean at subsequent points of measurement. This phenomenon may explain why we observed decreased symptoms at age 22 years among those with the highest symptom levels at age 20, as well as increased symptoms at age 22 years among those with the lowest levels of pre-existing symptoms at age 20 .

Altogether, these conflicting findings about the mental health consequences of the pandemic may be attributed to several different factors. Firstly, changes in depression and anxiety symptoms might vary according to the type and severity of government lockdown measures in place when symptoms were assessed [2]. Indeed, the systematic review of longitudinal studies by Robinson and colleagues mentioned above found that while there was an overall increase in mental health symptoms from before to during pandemic, this increase was most pronounced during the early stages of the pandemic (March-April 2020) before decreasing back toward pre-pandemic levels over the following months (May-July 2020). Data for the current study was collected in July-August 2020, during which time Quebecers were newly permitted to gather in private (up to 10 people from 3 different households) and public settings (up to 50 people in movie theaters, reception halls, and places of worship, among other locations) after months of strict lockdown [23]. Participants' newfound ability to socialize after months of isolation may have offset the impact of pandemic-related stress experienced during the strict lockdown period. Indeed, a German study examining the effects of different kinds and levels of restrictive public health measures during the pandemic (e.g., quarantine/lockdown/stay-at-home orders) on symptoms of anxiety and depression found that stricter restrictions, greater reduction of social 
contact, and greater perceived changes in daily life were associated with poorer mental health [2].

Secondly, depression and anxiety symptoms may vary in accordance with government socioeconomic policies, which differ across countries. Soon after the onset of the pandemic, the Canadian government introduced relatively generous payments for workers and postsecondary students whose income earning abilities were negatively impacted (e.g., reduction in hours; job loss) by the COVID-19 pandemic [3, 16]. These government measures may have had a protective effect against depression and anxiety. For example, a survey study using data collected by the US Census Bureau from April to July 2020 found that the prevalence of depressive and anxiety symptoms varied across states by what the investigators called "household income shock" [8] (i.e., the experience of job loss and/or partial income loss), which was buffered by state-level differing socioeconomic policies (e.g., access to Medicaid, unemployment insurance, and suspended utility shut-offs) [8]. Despite the potentially buffering effects of the Canadian government's economic response plan against symptoms of depression and anxiety, it is worth noting that future professional opportunities were still among the primary COVID-related concerns shared by young adults, with $21.4 \%$ of our participants stating that they were very or extremely concerned by future job prospects (see Fig. 1).

Lastly, the normal process of psychological adaptation following distressing events might also come into play in explaining the inconsistent findings on the impact of the pandemic on the mental health of young adults $[6,34]$. Consistent with findings from a meta-analysis indicating that mental health deteriorated at the onset of the pandemic before returning to baseline levels by mid-2020 [40], a prospective longitudinal study in the UK examining anxiety and depression over the first 20 weeks of lockdown (March 23-August 9, 2020) found that there was a significant decrease in depressive and anxiety symptoms throughout both the strict lockdown period and the period during which lockdown measures were eased [11]. Moreover, the same study found that younger adults showed faster improvements in depression and anxiety symptoms compared to older adults [11]. This suggests that while some studies find young adults to be at greater risk for mental health problems during the pandemic, they may be better able to psychologically adapt to challenging circumstances relative to older adults, or that factors contributing to persistent internalizing symptoms may have been alleviated by the confinement measures (e.g., lack of commute; additional rest time; accommodations for final exams). However, given that most studies on the mental health impact of the COVID-19 pandemic on young adults were conducted during the first wave of the pandemic in 2020, the mental health impact of the subsequent waves is still unclear.

\section{Methodological considerations}

This study has a number of strengths, including its longitudinal design; the use of standardized measures of depression and anxiety; and data collected before and during the pandemic from the same participants. We acknowledge the following limitations. As in all longitudinal surveys, attrition occurred over the years and the most vulnerable individuals were underrepresented. Although all analyses were weighted, such differential attrition could potentially result in underestimation of the rates of anxiety and depression and consequently of the mental impact of COVID-19. Mental health outcomes were measured by self-report questionnaires, which do not provide clinical diagnoses. While we were able to use longitudinal data with mental health assessments before and during the COVID-19 pandemic, it is difficult to differentiate between mental health changes attributable to the pandemic versus developmental changes that are typical for this age group or changes due to seasonal effects, since pre-pandemic measures were obtained in the spring, while intra-pandemic measures were collected during the summer.

\section{Conclusion}

In this sample of young adults from the Canadian province of Québec, we found that depressive and anxiety symptoms did not significantly change during the first wave of the COVID-19 pandemic, although the prevalence of severe depression did slightly increase, especially among those who were living alone during the lockdown. Moreover, while the majority of the young adults showed a pattern of symptoms consistent with adaptation to the pandemic, levels of depressive and anxiety symptoms increased among those with the lowest levels of symptoms before the pandemic. Future studies should track the mental health of young adults throughout the subsequent waves of the COVID-19 pandemic to better understand whether this observation reflets a regression to the mean or a need to improve access to mental health services for youth who are newly struggling with symptoms of depression and anxiety. 


\section{Supplementary Information}

The online version contains supplementary material available at https://doi. org/10.1186/s12991-021-00362-2.

Additional file 1: Table S1. Change in depression and anxiety symptoms from before to during the COVID-19 pandemic. Table S2. Change in depression and anxiety symptoms from before the pandemic to during the pandemic according to different levels of symptoms severity before the pandemic

\section{Acknowledgements}

The larger Quebec Longitudinal Study of Child Development was supported by funding from the Quebec provincial government's Ministry of Health and Ministry of Family Affairs, the Lucie and André Chagnon Foundation, the Fonds de Recherche du Québec en Société et Culture, Canada's Social Sciences and Humanities Research Council, the Canadian Institutes of Health Research, the Centre Hospitalier Universitaire de Sainte-Justine, and the Institut de la Statistique du Québec. The authors thank Alain Girard and Elise Chartrand for their contributions to the statistical analysis and all participants of the Quebec Longitudinal Study of Child Development.

\section{Authors' contributions}

Each author has sufficiently contributed to the manuscript to justify authorship and responsibility for the content. KW-M, M-CG, and MO conceived and designed the study. MB, RT, M-CG, and SC acquired the data. M-CG analyzed the data and all of the authors interpreted the data. KW-M, M-CG, and MO wrote the initial drafts, and SL, J-PG, IO-M, NC, FP, MB, RT, M-HP, NC-R, and SC revised the paper for important intellectual content. All of the authors read and gave their final approval of the version to be published and agreed to be accountable for all aspects of the work.

\section{Funding}

This project was supported by l'Observatoire sur l'Éducation et la Santé des Enfants, funded by FRQ-SC. Drs Pennestri, Chadi and Castellanos-Ryan hold a Junior 1 salary award from the Fonds de recherche du Québec en sante (FRQS). Drs Gouin, Ouellet-Morin, Boivin, Tremblay, and Geoffroy hold a Canada Research Chair.

\section{Availability of data and materials}

The data that support the findings of this study are available from the Quebec Longitudinal Study on Child Development (QLSCD) but restrictions apply to the availability of these data. Data access QLSCD data are accessible to researchers on the premises of the Centre d'accès aux données de recherche de l'Institut statistique du Quebec (CADRISQ) located in Montreal and Quebec City. To access the data, researchers affiliated with an institution in Quebec must create a profile and fill out an access request including, among other things, the purpose and aim of the research project, a summary of the analysis plan, the contact information of any researchers associated with the project, and the location where they want to use the data. Once received, the access request is analyzed by the Research Data Access Point team, which makes the necessary follow-up to obtain the required authorizations and communicates the results to the researchers. Researchers receive the necessary support for the submission of their access request and the implementation of their projects. More information can be found on the Research Data Access Point website (https://www.stat.gouv.qc.ca/research/\#/accueil). Numerous international collaborations have been established since the start of the study.

\section{Declarations}

\section{Ethics approval and consent to participate}

The Quebec Longitudinal Study on Child Development (QLSCD), conducted by the Institut de la Statistique du Québec (ISQ), was approved by ethical committees of the ISQ and the CHU Sainte-Justine Hospital Research Centre and written informed consent was obtained.

\section{Consent for publication}

Not applicable.

\section{Competing interests}

None declared.

\section{Author details}

${ }^{1}$ Department of Psychiatry, McGill Group for Suicide Studies, Douglas Mental Health University Institute, Montreal, QC, Canada. ${ }^{2}$ Department of Educational and Counselling Psychology, McGill University, Montreal, QC H3A 1Y2, Canada. ${ }^{3}$ Hôpital en Santé Mentale Rivière-des-Prairies (CIUSSS-NIM), Montreal, QC, Canada. ${ }^{4}$ Department of Psychology, University of Montreal, Montreal, QC, Canada. ${ }^{5}$ School of Psychoeducation, University of Montreal, Montreal, QC, Canada. ${ }^{6} \mathrm{CHU}$ Ste-Justine Research Centre, Montreal, QC, Canada. ${ }^{7}$ Department of Pediatrics, University of Montreal, Montreal, QC, Canada. ${ }^{8}$ Educational Sciences, Laval University, Quebec, QC, Canada. ${ }^{9}$ Department of Psychology, Concordia University, Montreal, QC, Canada. ${ }^{10}$ School of Criminology, University of Montreal, Montreal, QC, Canada. ${ }^{11}$ Research Center of the Montreal Mental Health University Institute, Montreal, QC, Canada. ${ }^{12}$ Department of Psychology, UQAM, Montreal, QC, Canada. ${ }^{13}$ School of Psychology, Laval University, Quebec, QC, Canada. ${ }^{14}$ Department of Social and Preventive Medicine, University of Montreal, Quebec, Canada. ${ }^{15}$ Bordeaux Population Health, Université de Bordeaux, INSERM 1219, Bordeaux, France.

Received: 1 July 2021 Accepted: 11 August 2021

Published online: 08 September 2021

\section{References}

1. Amsalem D, Dixon LB, Neria Y. The coronavirus disease 2019 (COVID-19) outbreak and mental health: current risks and recommended actions. JAMA Psychiat. 2021;78:9. https://doi.org/10.1001/jamapsychiatry.2020. 1730

2. Benke C, Autenrieth LK, Asselmann E, Pané-Farré CA. Lockdown, quarantine measures, and social distancing: associations with depression, anxiety and distress at the beginning of the COVID-19 pandemic among adults from Germany. Psychiatry Res. 2020;293: 113462. https://doi.org/ 10.1016/j.psychres.2020.113462.

3. Canada Revenue Agency. Canada Emergency Student Benefit (CESB) [WWW Document]. Canada Revenue Agency, Canada Emergency Student Benefit (CESB). 2020. URL https://www.canada.ca/en/revenueagency/services/benefits/emergency-student-benefit.html Accessed 13 Apr 2021.

4. Caron J. Une validation de la forme abrégée de l'Échelle de provisions sociales : I'ÉPS-10 items. smq. 2013;38:297-318. https://doi.org/10.7202/ 1019198ar.

5. Copeland WE, McGinnis E, Bai Y, Adams Z, Nardone H, Devadanam V, Rettew J, Hudziak JJ. Impact of COVID-19 pandemic on college student mental health and wellness. J Am Acad Child Adolesc Psychiatry. 2021:60:134-141.e2. https://doi.org/10.1016/j.jaac.2020.08.466.

6. Daly M, Robinson E. Psychological distress and adaptation to the COVID19 crisis in the United States. J Psychiatr Res. 2021;136:603-9. https://doi. org/10.1016/j.jpsychires.2020.10.035

7. Données COVID-19 par région sociosanitaire [WWW Document]. INSPQ. 2021. URL https://www.inspq.qc.ca/covid-19/donnees/par-region. Accessed 15 Mar 2021.

8. Donnelly R, Farina MP. How do state policies shape experiences of household income shocks and mental health during the COVID-19 pandemic? Soc Sci Med. 2021;269: 113557. https://doi.org/10.1016/j.socscimed.2020. 113557.

9. Étude longitudinale du développement des enfants du Québec (ELDEQ) [WWW Document], n.d. https://www.jesuisjeserai.stat.gouv.qc.ca/. Accessed 9 Mar 2021

10. Fancourt, D., Steptoe, A., 2020. COVID-19 social study. Covid-19 Social Study UCL. https://www.covidsocialstudy.org/results. Accessed 11 Mar 2021

11. Fancourt D, Steptoe A, Bu F. Trajectories of anxiety and depressive symptoms during enforced isolation due to COVID-19 in England: a longitudinal observational study. The Lancet Psychiatry. 2021;8:141-9. https://doi. org/10.1016/S2215-0366(20)30482-X. 
12. Fergusson DM, McLeod GFH, Horwood LJ, Swain NR, Chapple S, Poulton R. Life satisfaction and mental health problems (18 to 35 years). Psychol Med. 2015;45:2427-36. https://doi.org/10.1017/S0033291715000422.

13. Ferro MA, Gorter JW, Boyle MH. Trajectories of depressive symptoms in Canadian emerging adults. Am J Public Health. 2015;105:2322-7. https:// doi.org/10.2105/AJPH.2015.302817.

14. Goldman-Mellor S, Caspi A, Arseneault L, Ajala N, Ambler A, Danese A, Fisher H, Hucker A, Odgers C, Williams T, Wong C, Moffitt TE. Committed to work but vulnerable: self-perceptions and mental health in NEET 18-year olds from a contemporary British cohort. J Child Psychol Psychiatry. 2016;57:196-203. https://doi.org/10.1111/jcpp.12459.

15. González-Sanguino C, Ausín B, Castellanos MÁ, Saiz J, López-Gómez A, Ugidos C, Muñoz M. Mental health consequences during the initial stage of the 2020 Coronavirus pandemic (COVID-19) in Spain. Brain Behav Immun. 2020;87:172-6. https://doi.org/10.1016/j.bbi.2020.05.040.

16. Government of Canada, Department of Finance. Canada's COVID-19 economic response plan [WWW Document]. aem. 2020. https://www. canada.ca/en/department-finance/economic-response-plan.html. Accessed 7 Apr 2021.

17. Hamza CA, Ewing L, Heath NL, Goldstein AL. When social isolation is nothing new: a longitudinal study psychological distress during COVID19 among university students with and without preexisting mental health concerns. Can Psychol. 2020. https://doi.org/10.1037/cap0000255.

18. Holmes EA, O'Connor RC, Perry VH, Tracey I, Wessely S, Arseneault L, Ballard C, Christensen H, Silver RC, Everall I, Ford T, John A, Kabir T, King K, Madan I, Michie S, Przybylski AK, Shafran R, Sweeney A, Worthman CM, Yardley L, Cowan K, Cope C, Hotopf M, Bullmore E. Multidisciplinary research priorities for the COVID-19 pandemic: a call for action for mental health science. The Lancet Psychiatry. 2020;7:547-60. https://doi.org/10. 1016/S2215-0366(20)30168-1.

19. Jurewicz I. Mental health in young adults and adolescents-supporting general physicians to provide holistic care. Clin Med (Lond). 2015;15:1514. https://doi.org/10.7861/clinmedicine.15-2-151.

20. Lai J, Ma S, Wang Y, Cai Z, Hu J, Wei N, Wu J, Du H, Chen T, Li R, Tan H, Kang L, Yao L, Huang M, Wang H, Wang G, Liu Z, Hu S. Factors associated with mental health outcomes among health care workers exposed to coronavirus disease 2019. JAMA Netw Open. 2020. https://doi.org/10.1001/ jamanetworkopen.2020.3976.

21. Lesser IA, Nienhuis CP. The impact of COVID-19 on physical activity behavior and well-being of Canadians. Int J Environ Res Public Health. 2020;17:3899. https://doi.org/10.3390/ijerph17113899.

22. Li HY, Cao H, Leung DYP, Mak YW. The psychological impacts of a COVID19 outbreak on college students in China: a longitudinal study. Int J Environ Res Public Health. 2020;17:3933. https://doi.org/10.3390/ijerp h17113933.

23. Liste de toutes les infographies en lien avec les annonces du premier ministre (COVID-19) [WWW Document], 2021. Quebec.ca. https://www. quebec.ca/premier-ministre/premier-ministre/versions-accessiblesannonces-premier-ministre-covid19/liste-toutes-infographies-annoncespremier-ministre-covid19. Accessed 7 Apr 2021.

24. Lucassen MF, Stasiak K, Samra R, Frampton CM, Merry SN. Sexual minority youth and depressive symptoms or depressive disorder: a systematic review and meta-analysis of population-based studies. Aust N Z J Psychiatry. 2017;51:774-87. https://doi.org/10.1177/0004867417713664.

25. Mazza C, Ricci E, Biondi S, Colasanti M, Ferracuti S, Napoli C, Roma P. A Nationwide survey of psychological distress among Italian people during the COVID-19 pandemic: immediate psychological responses and associated factors. Int J Environ Res Public Health. 2020;17:3165. https://doi.org/ 10.3390/ijerph17093165.

26. McGinty EE, Presskreischer R, Han H, Barry CL. Psychological distress and loneliness reported by US adults in 2018 and April 2020. JAMA. 2020;324:93. https://doi.org/10.1001/jama.2020.9740.

27. Mojtabai R, Olfson M, Han B. National trends in the prevalence and treatment of depression in adolescents and young adults. Pediatrics. 2016. https://doi.org/10.1542/peds.2016-1878.

28. Orri M, Boivin M, Chen C, Ahun MN, Geoffroy M-C, Ouellet-Morin I, Tremblay RE, Côté SM. Cohort profile: Quebec longitudinal study of child development (QLSCD). Soc Psychiatry Psychiatr Epidemiol. 2020. https:// doi.org/10.1007/s00127-020-01972-z.
29. Özdin S, Bayrak Özdin Ş. Levels and predictors of anxiety, depression and health anxiety during COVID-19 pandemic in Turkish society: the importance of gender. Int J Soc Psychiatry. 2020;66:504-11. https://doi.org/10. $1177 / 0020764020927051$.

30. Pan K-Y, Kok AAL, Eikelenboom M, Horsfall M, Jörg F, Luteijn RA, Rhebergen D, van Oppen P, Giltay EJ, Penninx BWJH. The mental health impact of the COVID-19 pandemic on people with and without depressive, anxiety, or obsessive-compulsive disorders: a longitudinal study of three Dutch case-control cohorts. The Lancet Psychiatry. 2021;8:121-9. https:// doi.org/10.1016/S2215-0366(20)30491-0.

31. Pascoe JM, Wood DL, Duffee JH, Kuo A, Committee on Psychosocial Aspects of Child and Family Health. Mediators and adverse effects of child poverty in the United States. Pediatrics. 2016. https://doi.org/10. 1542/peds.2016-0340.

32. Pelto-Piri V, Wallsten T, Hylén U, Nikban I, Kjellin L. Feeling safe or unsafe in psychiatric inpatient care, a hospital-based qualitative interview study with inpatients in Sweden. Int J Ment Health Syst. 2019;13:23. https://doi. org/10.1186/s13033-019-0282-y.

33. Pfefferbaum B, North CS. Mental health and the Covid-19 pandemic. N Engl J Med. 2020;383:510-2. https://doi.org/10.1056/NEJMp2008017.

34. Pierce M, McManus S, Jessop C, John A, Hotopf M, Ford T, Hatch S, Wessely S, Abel KM. Says who? The significance of sampling in mental health surveys during COVID-19. The Lancet Psychiatry. 2020;7:567-8. https:// doi.org/10.1016/\$2215-0366(20)30237-6.

35. Poulin C, Hand D, Boudreau B. Validity of a 12-item version of the CES-D used in the National Longitudinal Study of Children and Youth. Chronic Dis Can. 2005;26:65-72.

36. Qiu J, Shen B, Zhao M, Wang Z, Xie B, Xu Y. A nationwide survey of psychological distress among Chinese people in the COVID-19 epidemic: implications and policy recommendations. Gen Psychiatr. 2020;33: e100213. https://doi.org/10.1136/gpsych-2020-100213.

37. Radloff LS. The CES-D scale: a self-report depression scale for research in the general population. Appl Psychol Meas. 1977;1:385-401. https://doi. org/10.1177/014662167700100306.

38. Rapisarda F, Vallarino M, Cavallini E, Barbato A, Brousseau-Paradis C, De Benedictis $L$, Lesage A. The early impact of the Covid-19 emergency on mental health workers: a survey in Lombardy, Italy. IJERPH. 2020;17:8615. https://doi.org/10.3390/ijerph17228615.

39. Robillard R, Daros AR, Phillips JL, Porteous M, Saad M, Pennestri M-H, Kendzerska T, Edwards JD, Solomonova E, Bhatla R, Godbout R, Kaminsky Z, Boafo A, Quilty LC. Emerging New psychiatric symptoms and the worsening of pre-existing mental disorders during the COVID-19 pandemic: a Canadian multisite study: Nouveaux symptômes psychiatriques émergents et détérioration des troubles mentaux préexistants durant la pandémie de la COVID-19: une étude canadienne multisite. Can J Psychiatry. 2021. https://doi.org/10.1177/0706743720986786.

40. Robinson E, Sutin AR, Daly M, Jones A. A systematic review and metaanalysis of longitudinal cohort studies comparing mental health before versus during the COVID-19 pandemic (preprint). Psychiatry Clin Psychol. 2021. https://doi.org/10.1101/2021.03.04.21252921.

41. Scardera S, Perret LC, Ouellet-Morin I, Gariépy G, Juster R-P, Boivin M, Turecki G, Tremblay RE, Côté S, Geoffroy M-C. Association of social support during adolescence with depression, anxiety, and suicidal ideation in young adults. JAMA Netw Open. 2020;3: e2027491. https://doi.org/10. 1001/jamanetworkopen.2020.27491.

42. Shanahan L, Steinhoff A, Bechtiger L, Murray AL, Nivette A, Hepp U, Ribeaud $D$, Eisner M. Emotional distress in young adults during the COVID-19 pandemic: evidence of risk and resilience from a longitudinal cohort study. Psychol Med. 2020. https://doi.org/10.1017/S003329172 000241X.

43. Spitzer RL, Kroenke K, Williams JBW, Löwe B. A brief measure for assessing generalized anxiety disorder: the GAD-7. Arch Intern Med. 2006;166:1092. https://doi.org/10.1001/archinte.166.10.1092.

44. Tu MT., Desrosiers H. La satisfaction à l'égard de la vie lors du passage à l'âge adulte: Étude longitudinale de développement des enfants du Québec (ELDEQ). Institut de la statistique du Québec; 2019. vol 9, p. 2

45. Varma P, Junge $M$, Meaklim $H$, Jackson ML. Younger people are more vulnerable to stress, anxiety and depression during COVID-19 pandemic; 
a global cross-sectional survey. Prog Neuropsychopharmacol Biol Psychiatry. 2021;109: 110236. https://doi.org/10.1016/.jpnpbp.2020.110236.

46. Willms JD, Shields M. A measure of socioeconomic status for the National Longitudinal Survey of Children and Youth. Canada: Atlantic Center for Policy Research in Education, University of New Brunswick and Statistics Canada; 1996

47. Wilson AM, Deri Armstrong C, Furrie A, Walcot E. The mental health of Canadians with self-reported learning disabilities. J Learn Disabil. 2009;42:24-40. https://doi.org/10.1177/0022219408326216.
48. Zhou J, Liu L, Xue P, Yang X, Tang X. Mental health response to the COVID19 outbreak in China. AJP. 2020;177:574-5. https://doi.org/10.1176/appi. ajp.2020.20030304

\section{Publisher's Note}

Springer Nature remains neutral with regard to jurisdictional claims in published maps and institutional affiliations.
Ready to submit your research? Choose BMC and benefit from:

- fast, convenient online submission

- thorough peer review by experienced researchers in your field

- rapid publication on acceptance

- support for research data, including large and complex data types

- gold Open Access which fosters wider collaboration and increased citations

- maximum visibility for your research: over $100 \mathrm{M}$ website views per year

At BMC, research is always in progress.

Learn more biomedcentral.com/submissions 